\title{
Participação das perícias em sentenças para o julgamento de crimes militares
}

\author{
J.C. Haeffner ${ }^{a}$, E.H.A. Souza ${ }^{a}$, F.C. Pereira ${ }^{b}$, C. Haeffner ${ }^{c}$, L.L. Guimarães ${ }^{d}$, E.H.A. Souza ${ }^{e^{*}}$ \\ ${ }^{a}$ Mestres pelo Programa de Mestrado Acadêmico em Perícias Forenses da Faculdade de Odontologia da Universidade de Pernambuco (FOP/UPE), \\ Camaragibe (PE), Brasil. \\ ${ }^{b}$ Responsável técnico pela análise estatística dos dados e Professor da Faculdade de Odontologia da Universidade de Pernambuco (FOP/UPE), \\ Camaragibe (PE), Brasil. \\ ' Aluna do Programa de Doutorado Acadêmico Educação em Ciências Química da Vida e Saúde pela Universidade Federal do Rio Grande do Sul \\ (UFRGS), Porto Alegre (RS), Brasil. \\ ${ }^{d}$ Professora do Departamento de Patologia do Instituto de Ciências Biológicas da Universidade de Pernambuco, Recife (PE), Brasil. \\ e Orientadora da Dissertação que deu origem ao artigo e à época Professora do Programa de Mestrado Acadêmico em Perícias Forenses da \\ Faculdade de Odontologia da Universidade de Pernambuco (FOP/UPE), Camaragibe (PE), Brasil.
}

*Endereço de e-mail para correspondência: e.ha.souza@hotmail.com/hffjoao@gmail.com Tel.: +55-81-997076666/997657915.

\begin{abstract}
Resumo
Crime militar tem seu processo de ação penal conduzido pela Justiça Militar da União (JMU), considerada ramo da Justiça Especializada brasileira. Almejou-se verificar a participação da perícia na sentença de processos destinados aos julgamentos de crimes militares. Foi realizado estudo descritivo, de corte transversal, documental e quantitativo que utilizou dados de amostra com 136 processos sentenciados em uma das auditorias da JMUe que continham perícia. A amostra apontou que a perícia mais encontrada foi a do tipo contábil (26,3\%). Predominou a vinculação militar do perito $(59,5 \%)$ e no segmento civil, o Instituto de Criminalística Professor Armando Samico (16,9\%). Houve condenação do réu na maioria dos casos $(70,6 \%)$. A perícia foi aceita em $99,3 \%$ dos processos, sendo citada e mencionada no corpo da sentença proferida em $75 \%$ deles sendo a diferença entre os grupos instituídos, estatisticamente significante $(\mathrm{p}=0,03)$. Assim o laudo pericial como elemento probatório, ao contribuir na determinação da culpa, constitui-se elemento de valor nos casos de condenação penal do réu.
\end{abstract}

Palavras-Chave: Crime. Processo Legal. Prova Pericial.

\begin{abstract}
Military crime has its criminal prosecution process conducted the Union's Military Justice (JMU), considered a branch of the brazilian Specialized Justice. It is hoped to verify the participation of the expert in the sentence of processes destined to the judgments of military crimes. A descriptive, cross sectional documentary and quantitative study was carried out which used sample data with 136 sentenced cases in one of the JMU audits and which contained expertise. The sample found the most common was the type of accounting (26.3\%). Predominated military attachment of the expert $(59.5 \%)$ and in the civil segment to the Institute of Criminalistics Professor Armando Samico (16.9\%). The defendant was convicted in most cases (70.6\%). The expert opinion was accepted in $99.3 \%$ of the cases, being cited and mentioned in the body of the sentence handed down in $75 \%$ of them; and the difference between the established groups, statistically significant $(\mathrm{p}=0.03)$. Thus, the expert report as a probative element, when contributing to the determination of guilt, constitutes an element of value in cases of criminal conviction of the defendant.
\end{abstract}

Keywords: Crime. Legal Process. Expert Testimonio.

\section{INTRODUÇÃO}

A busca por uma definição ampla e formal para o crime, remonta historicamente a 1830, sendo encontrada, no código criminal do Império. Neste código o crime é entendido como toda ação ou omissão contrária às leis penais [1]. Relativo ao crime militar este pode ser definido como toda ação executada por militar do efetivo de uma corporação castrense ou desenrolada dentro de região territorial sob administração militar, que configure violação à especificação contida em uma das leis integrantes do acervo textual normativo do Código Penal Militar - CPM [2,3]. 
Para o julgamento de um crime militar se alça mão do processo de ação penal militar,com início pela aceitação de uma denúncia deflagrada pelo Ministério Público Militar até a sua finalização marcada pela sentença. $\mathrm{O}$ oficio de realizar os atos que compõem este processo compete a um dos três ramos que representam a existência da Justiça Especializada Brasileira; ramo este denominado de Justiça Militar. Neste ramo do judiciário se constitui a Justiça Militar da União (JMU), uma organização funcional encarregada do processo destinado aos crimes militares ligados às três corporações militares nacionais: a Marinha do Brasil - MB; o Exército Brasileiro - EB e a Força Aérea Brasileira - FAB [4,5].

Focado nesta função constitucional, a JMU segue o desenvolvimento de atos processuais dispostos no Código Processual Penal Militar - CPPM, onde em sua estrutura se faz presente um título acerca de atos probatórios, incluindo capítulo destinado a englobar regulamentação processual sobre o assunto das perícias e exames [6,7].

Neste modelo processual, prova é todo meio destinado a idear o convencimento do juiz, seu destinatário, a respeito da verdade de um fato denunciado e levado a julgamento. Pode ser representada, pelo meio probatório da perícia, como uma apontadora da materialidade do crime e da maneira de ação do criminoso. A perícia atua pela execução de exame que vasculha fontes reais, resultante do trabalho de natureza técnica e científica, executado pelo perito; fomentando o elo de relação entre a Ciência e a Justiça $[8,9,10]$.

A sentença em um processo da JMU, dada por um juízo colegiado formado em primeiro grau por um juiz togado e quatro militares da ativa, ilustra o julgamento do mérito ao réu no tocante ao crime militar cometido, tendo na sua composição um relatório que sumariza o processo e uma fundamentação que reflete as situações que conferem sustentação legal. Neste tópico sentencial a menção a perícia contida dos autos tem a possibilidade de lhe conferir uma participação com papel como elemento de prova por fomentar o embasamento da decisão proclamada pela autoridade judiciária, seja de uma condenação ou absolvição do réu. [11,12,13].

Ao ser buscar acervo referenciando sobre participação da perícia em sentenças de processos penais transcorridos na esfera especializada da JMU, se evidencia insuficiência de textos, ainda que seja possível encontra-los junto a outras esferas do Direito. Tal escassez, é corroborada por Ribeiro (2013) ao afirmar que "A Justiça Militar, como ramo especializado do Poder Judiciário, é ainda uma desconhecida da maior parte dos cidadãos e mesmo dos profissionais do Direito [14]".

Dessa forma se procurou, em pesquisa que resultou no presente artigo, levantar as características quanto ao papel da perícia na sentença emitida pelas autoridades judiciárias na primeira instância da JMU de forma a contribuir no fortalecimento interdisciplinar entre Direito e a perícia como meio probatório, na difusão ampla do conhecimento levantado e no reconhecimento público deste elemento para garantia do cumprimento das leis nacionais vigentes.

\section{MATERIAL E MÉTODOS}

O estudo pode ser tipificado como descritivo analítico, por descrever a realidade sem nela intervir; de corte transversal, ao gerar um instantâneo da realidade em um ponto especifico do tempo; documental por utilizar documento jurídico como material de consulta no levantamento das informações de interesse do pesquisador e,quantitativo ao usar técnicas estatísticas, na coleta e tratamento das informações procurando evitar distorções de análise e de interpretação conferindo desta forma uma maior margem de segurança nas conclusões formuladas.

Relativo às questões bioéticas, em observância as normativas estabelecidas pela Resolução no 466 de 12 de dezembro de 2012 [15], da Comissão Nacional de Ética em Pesquisa - CONEP, foi solicitada anuência ao órgão detentor do acervo processual a ser pesquisado, representado pela Auditoria da $7^{\mathrm{a}}$ Circunscrição da Justiça Militar - $7^{\mathrm{a}}$ CJM, que desempenha seu trabalho jurídico, de primeira instância da JMU, na área geográfica dos estados brasileiros de Alagoas, Pernambuco, Paraíba e Rio Grande do Norte. Com tal anuência o projeto foi submetido ao Comitê de Ética Pesquisa em Seres Humanos da Universidade de Pernambuco - UPE, sendo aprovado pelo Parecer No $N^{\circ}$.547.742.

Para estabelecimento do tamanho amostral, tomou-se por base a informação prestada pela Secretaria da Auditoria da $7^{\text {a }}$ CJM. Entre 2010 e 2014 foi contabilizado um total de duzentos e oitenta e oito (288) processos sentenciados. Aplicando-se a fórmula para população finita e admitindo-se uma margem de erro de 5\%, chegouse ao número de cento e nove (109) processos. Um percentual de $20 \%$ foi aplicado para compensar eventuais perdas ficando a amostra final constituída por 133 processos.

Como critério de inclusão para ser incluído na amostra o processo deveria possuir em seu conteúdo textual algum tipo de laudo onde se materializasse a perícia e ter sido sentenciado, estando em condição de processo finalizado transitado em julgado.

Os dados de interesse, extraídos da leitura, foram compilados em uma ficha construída para tal fim sendo, posteriormente digitados em planilha eletrônica do programa estatístico Statistical Package for the Social Sciences-SPSS Software ${ }^{\circledR}$, na versão 13.0 for Windows, constituindo banco de dados a ser analisado.

Para análise descritiva testes paramétricos (média) e não paramétricos (mediana e moda) foram aplicados. E na análise inferencial para se verificar a importância da participação da perícia no processo como elemento que 
contribuiu no estabelecimento da culpa ou não do réu julgado, estabeleceu-se como grupos a serem considerados na comparação: citados condenados/não condenados; e citados e mencionados condenados/não condenados, sendo a eventual diferença entre eles testada pelo qui-quadrado $\left(x^{2}\right)$ de Pearson.

\section{RESULTADOS}

A coleta de dados realizada no arquivo da Auditoria da $7^{\text {a }}$ CJM foi iniciada pelo processo finalizado, transitado em julgado, mais recentemente recebido até ser atingido o total de processos estabelecidos para a amostra $(\mathrm{N}=133)$. Durante o levantamento porém evidenciou-se existirem mais três processos que atendiam aos critérios de inclusão, motivo pelo qual eles foram igualmente incluídos, chegando-se assim a um total de 136 processos.

Na caracterização geográfica dos 136 casos,pode ser verificado que $92(68 \%)$ foram procedentes de Pernambuco, sendo 77 deles $(56,6 \%)$ da cidade de Recife.

Quanto ao número de réus envolvidos, em uma parcela expressiva dos processos $(81,6 \%)$ prevaleceu a participação de apenas um elemento. Relativo à graduação/posto, $59,0 \%$ dos réus eram soldados, seguidos pelos civis que representaram $28 \%$ dos casos. Cento e vinte e oito $(68,9 \%)$ dos réus, encontravam-se na faixa etária de 18 a 29 anos; 159 (85,5\%) eram do sexo masculino e 135 (72,3\%) do estado civil solteiro. No que tange a distribuição dos réus nas três forças armadas:93 (68,4\%) do Exército Brasileiro - EB; 28 (20,3\%) da Força Aérea Brasileira - FAB e 15 (11\%) da Marinha do Brasil MB.

A distribuição dos casos segundo o tipo de crime praticado pode ser vista na Tabela 1 .

Relativo ao tipo de perícia, citada nos autos processuais, evidenciou-se que as de natureza contábil, traumatológica e química e/ou toxicológica foram predominantes $(26,3 \%, 24,3 \%$ e $16,6 \%$, respectivamente), como evidenciado na Tabela 2.

No contexto de vinculação do perito que executou a perícia, em $81(59,5 \%)$ dos casos os peritos eram militares; em 47 (34,5\%), eram civis e em oito (6\%), foi evidenciada dupla vinculação. Na ramificação militar, o perito em 65 (47,8\%) era do Exército Brasileiro - EB, em $14(10,3 \%)$ da Força Aérea Brasileira - FAB, oito $(5,9 \%)$ da Marinha do Brasil - MB e dois $(1,4 \%)$ de outras corporações. No segmento de pericia com vinculação civil pode ser visto o que se segue na tabela 3 .

A conclusão pericial foi aceita em 135 processos $(99,3 \%)$. A elaboração de novos quesitos pela autoridade judicial ou pelas partes ocorreu apenas em dois processos $(1,5 \%)$ e a solicitação de outra perícia pela autoridade judicial, em sete processos $(5,1 \%)$.

Tabela 1 - Distribuição da amostra segundo crime militar julgado no

\begin{tabular}{l|c|c}
\hline \multicolumn{1}{c|}{$\begin{array}{c}\text { Crime militar tipificado pelo } \\
\text { Código Penal Militar (CPM) }\end{array}$} & $\begin{array}{c}\text { N } \\
(\mathbf{1 3 6 )}\end{array}$ & $\begin{array}{c}\mathbf{\%} \\
\mathbf{( 1 0 0 , 0 )}\end{array}$ \\
\hline Art. 290 - Tráfico, posse ou uso de & & \\
entorpecente ou substância de efeito & 24 & 17,7 \\
similar & 18 & 13,3 \\
Art. 240 - Furto simples & 18 & 13,3 \\
Art. 251 - Estelionato & 15 & 11,1 \\
Art. 248 - Apropriação indébita & 12 & 8,9 \\
Art. 187 - Deserção & 7 & 5,2 \\
Art. 312 - Falsidade ideológica & 6 & 4,4 \\
Art. 195 - Abandono de posto & 6 & 4,4 \\
Art. 303 - Peculato & 5 & 3,7 \\
Art. 210 - Lesão Culposa & 4 & 3,0 \\
Art. 209 - Lesão Leve & 4 & 3,0 \\
Art. 163 - Recusa de obediência & 3 & 2,2 \\
Art. 205 - Homicídio & 2 & 1,4 \\
Art. 254 - Receptação & 2 & 1,4 \\
Art. 302 - Ingresso clandestino & 2 & 1,4 \\
Art. 203 - Dormir em serviço & 1 & 0,7 \\
Art. 223 - Ameaça & 1 & 0,7 \\
Art. 238 - Ato obsceno & 1 & 0,7 \\
Art. 259 - Dano simples & 1 & 0,7 \\
Art. 299 - Desacato a militar & 1 & 0,7 \\
Art. 301 - Desobediência & 1 & 0,7 \\
Art. 315 - Uso de documento falso & 1 & 0,7 \\
Art. 157 - Violência contra superior & 1 & 0,7 \\
Art. 175 - Violência contra inferior & & \\
\hline & Fonte: Pesquisa Direta
\end{tabular}

Tabela 2 - Caracterização da amostra segundo tipo de perícia realizada.

\begin{tabular}{l|c|c}
\hline \multicolumn{1}{c|}{ Tipo de perícia realizada } & $\mathbf{N}$ & $\mathbf{\%}$ \\
& $(\mathbf{1 4 4 )}$ & $\mathbf{( 1 0 0 , 0 )}$ \\
\hline Contábil & 38 & 26,3 \\
Traumatológica & 35 & 24,3 \\
Química e/ou Toxicológica & 24 & 16,6 \\
Avaliação de res furtiva & 18 & 12,5 \\
Documentoscópica e/ou grafotécnica & 10 & 7,0 \\
Local de crime & 7 & 4,9 \\
Balística & 6 & 4,2 \\
Psiquiátrica & 5 & 3,5 \\
Outras & 8 & 5,5 \\
& & \\
\hline \multicolumn{2}{|c}{ Fonte: Pesquisa Direta }
\end{tabular}

Tabela 3 - Caracterização da amostra segundo vínculo do perito civil 


\begin{tabular}{l|c|c}
\hline \multicolumn{1}{c|}{$\begin{array}{c}\text { *ivil } \\
\text { civão do perito }\end{array}$} & $\begin{array}{c}\mathbf{N} \\
\mathbf{( 1 3 6 )}\end{array}$ & $\begin{array}{c}\mathbf{\%} \\
\mathbf{( 1 0 0 , 0 )}\end{array}$ \\
\hline & & \\
IC - PE & 23 & 16,9 \\
SETEC/PF - PE & 14 & 10,2 \\
IML- PE & 7 & 5,1 \\
ITEP - RN & 4 & 2,0 \\
IPC - PB & 2 & 1,5 \\
IML- PE e IC - PE & 2 & 1,5 \\
CC - RN e SETEC/PF - RN & 1 & 0,7 \\
CML- RN & 1 & 0,7 \\
SETEC/PF- AL & 1 & 0,7 \\
Não se aplica & 81 & 59,6 \\
& & \\
\hline
\end{tabular}

Fonte: Pesquisa Direta

***

IC - PE Instituto de Criminalística Professor Armando Samico - Pernambuco

SETEC - Setor Técnico-Científico - Polícia

PF Federal

IML- PE Instituto de Medicina Legal Antonio

Persivo Cunha - Pernambuco

ITEP - Instituto Técnico-Científico de Polícia -

RN Rio Grande do Norte

IPC - PB Instituto de Polícia Científica - Paraíba

CC - RN Coordenadoria de Criminalística - Rio

Grande do Norte

CML - Coordenadoria de Medicina Legal - Rio

RN Grande do Norte

Em relação à finalização do processo, a sentença decretando condenação pode ser constatada em 96 (70,6\%) processos, com aplicação de pena de reclusão em $61(44,9 \%)$ e de detenção $35(25,7 \%)$ processos.

Buscando a participação da perícia nas sentenças que foram expedidas se verificou que em $102(75 \%)$ processos ela foi citada e mencionada, em $27(19,8 \%)$ ela foi apenas citada, e em sete $(5,2 \%)$ ela não foi nem citada nem mencionada.

Ao se comparar os grupos, "citada" e "citada e mencionada", vê-se que a citação e menção deste elemento (conteúdo do laudo pericial) pela autoridade judiciária no texto da sentença se deu em $59,7 \%$ dos casos sendo a diferença entre eles estatisticamente significante $(\mathrm{p}=0,03)$. Com isso não resta dúvida de sua relevância na atribuição da culpa e condenação do réu (Tabela 4).

Tabela 4 - Distribuição da amostra segundo a natureza da participação pericial na sentença e condenação ou não do réu.

\begin{tabular}{|c|c|c|c|c|c|c|}
\hline \multirow{3}{*}{$\begin{array}{c}\text { Participação } \\
\text { Pericial na } \\
\text { Sentença }\end{array}$} & \multicolumn{4}{|c|}{ CONDENAÇÃO } & \multirow{2}{*}{\multicolumn{2}{|c|}{ TOTAL }} \\
\hline & \multicolumn{2}{|c|}{ NÃO } & \multicolumn{2}{|c|}{ SIM } & & \\
\hline & $\mathrm{N}$ & $\%$ & $\mathrm{~N}$ & $\%$ & $\mathrm{~N}$ & $\%$ \\
\hline Citada & 13 & 10,1 & 14 & 10,8 & 27 & 20,9 \\
\hline $\begin{array}{l}\text { Citada e } \\
\text { mencionada }\end{array}$ & 25 & 19,4 & 77 & 59,7 & 102 & 79,1 \\
\hline BASE & 38 & 29,5 & 91 & 70,5 & 129 & 100,0 \\
\hline
\end{tabular}

\section{DISCUSSÃO}

$\mathrm{Na}$ Auditoria da $7^{\mathrm{a}}$ CJM, em cinco anos, 317 processos foram autuados, com isso o valor de 288 processos que foram sentenciados se encontra dentro da meta estipulada pelo Conselho Nacional de Justiça - CNJ da Justiça Militar da União - JMU de julgar 90\% desses processos.

Pernambuco e Recife, como esperado, foram o Estado e capital do nordeste brasileiro que mais contribuíram com número de casos ( $68 \%$ e $56,5 \%$, respectivamente) fato este explicado por reunir não apenas o maior número de organizações militares como também por concentrar o maior contingente de população militar.

Em relação às três forças militares, o Exército Brasileiro - EB desponta como a mais envolvida $(68,4 \%)$ por encerrar o maior número de efetivo no espaço geográfico da Auditoria da $7^{\mathrm{a}} \mathrm{CJM}$.

Relativo ao número de réus envolvidos houve predomínio dos casos em que apenas um réu esteve envolvido, sendo este perfil corroborado pelas pesquisas institucionais entre 2002-2012 e 2013-14 da JMU; não havendo também grande diferença no que tange os processos com cinco, seis e sete réus.

No tocante ao gênero do réu, na maioria da amostra predominou o masculino. Relativo à participação feminina nesses casos merece destaque o fato de que nos vinte e sete casos evidenciados elas eram procedentes do meio civil. Esse baixo número de mulheres militares envolvidas em crime militar talvez se deva ao relativo e recente ingresso desse estrato nas forças armadas.

Quanto à característica etária dos réus, predominou a faixa de 18 a 29 anos representando a maioria dos envolvidos $(68,9 \%)$. Relativo ao estado civil e a patente, os solteiros $(72,6 \%)$ e graduados como soldado $(59,8 \%)$ constituíram maioria corroborando conteúdo do referencial teórico. Considerando ser o serviço obrigatório exigido ao se completar 18 anos é de se esperar que esses jovens ainda não tenham contraído um relacionamento 
conjugal de matrimônio. $\mathrm{O}$ envolvimento em crimes desses jovens que estão, em sua maioria, cumprindo serviço militar obrigatório há pouco tempo, pode expor uma deficiência da estrutura pedagógica prévia à caserna, que não contribui para a prática de comportamentos compatíveis com os valores da cultura castrense.

Pela definição e tipificação dos crimes militares do CPM, nos processos com perícias, o delito mais praticado foi o tipificado como crime de Tráfico, posse e/ou uso de entorpecente (Artigo 290); dado este não corroborado no estudo efetivado pela JMU em que este delito ocupou a quinta posição. Em contrapartida, a mudança neste perfil de ocorrência pode estar atrelada à repercussão econômica que tal atividade representa para os que a praticam [16].

Referindo-se ao tipo de perícia, a mais realizada foi a contábil (26,3\%), relacionada de forma mais direta com os crimes do Artigo 251 - Estelionato e Artigo 248 Apropriação indébita, seguida da traumatológica (24,6\%), da química/toxicológica $(16,6 \%)$ e da avaliação da res furtiva $(12,5 \%)$. Cabe aqui se entender que há uma relação entre o tipo de perícia realizada e o tipo de elemento que o perito teve que realizar o ato pericial e a tipificação do crime cometido pelo réu.

A de natureza química, por exemplo, diz respeito ao exame realizado em droga bruta apreendida do réu traficante e a toxicológica em fluidos corporais do réu usuário. A do tipo traumatológica, por sua vez, que engloba o exame de lesão corporal, pode envolver não apenas os crimes de relação direta com uma lesão física da vítima, mas outras situações, de forma indireta, em que o réu foi preso em flagrante pelo cometimento de outro crime, como por exemplo, deserção.

Sobre a condição de vinculação do perito que executou a perícia presente nos autos pesquisados, predominou os militares vinculados ao EB. Esta predominância se explica primeiro pelo fato CPPM estabelecer a nomeação de preferência do perito milita; estando a nomeação de perito civil atrelada a inexistência de militar com atuação profissional exigida pelo caso para realizar a perícia. Referente ao perito vinculado a instituições civis constitui maioria os oriundos do Instituto de Criminalística Professor Armando Samico Pernambuco $(16,9 \%)$ e a explicação para isso passa pela existência neste órgão de estrutura laboratorial adequada a viabilização de perícias como as de natureza química e/ou toxicológica, não disponíveis no interior de organizações militares, locais onde os crimes foram perpetrados.

Com relação à conclusão pericial expressa no laudo elaborado pelo perito, na maioria dos casos $(99,3 \%)$ ela foi aceita integralmente não demandando formulação de novas questões nem a realização de nova perícia; salvo, nos casos em que foi necessário se complementar a perícia já realizada por outra de natureza diferente da primeira.

No que concerne à conclusão apresentada pela perícia, esta foi aceita integralmente pela autoridade judicial e pelas partes em 99,3\% dos casos não demandando formulação de novos quesitos, além dos já apresentados. Ainda assim e a titulo de complementação, novas perícias de natureza diferente da primeira, foram necessárias em $5,1 \%$ dos casos.

Sobre a condição de finalização do processo, a sentença foi pela condenação do réu em 70,6\% dos processos levantados e pela absolvição em 29,4\%. No grupo que recebeu a condenação, a pena mais aplicada foi a de reclusão (44,9\%), que inclui o cumprimento da pena em regime fechado, exigindo para isso um estabelecimento de segurança destinado a esta execução penal.

Relativo à variável participação da perícia na sentença proferida pela autoridade judicial ao réu se verificou que em 75\% dos casos ela foi citada e mencionada, e em $19,8 \%$ ela foi apenas citada. Para o entendimento da relevância desta variável, torna-se crucial especificar que a perícia foi considerada citada quando, no corpo textual da sentença, o magistrado considerou que esteve presente no processo, ou seja, constou dos autos. Referente à categoria de mencionada, esta foi concretizada por referência detalhada à perícia no segmento relativo à fundamentação, constitucionalmente obrigatória conforme inciso nove do Artigo. 93, da decisão sentenciada; sendo destacados pelo magistrado de forma substancial os relatos técnicos do perito, presentes no laudo, e seu papel de ter fornecido elemento de prova considerado pelo Juiz como contributivo a autoria, materialização, tipificação e gravidade do crime julgado.

Nos casos onde não ocorreu nem citação nem menção da perícia $(5,2 \%)$, apesar dela estar presente nos autos, isto pode ter decorrido do fato dela não guardar relação direta com o tipo de crime julgado; não configurando desta forma meio de prova processual, como em processo onde ocorreu prisão em flagrante, e no seguimento foi realizado exame de lesão corporal para registrar apenas a higidez física do réu.

Por fim, é importante se ressaltar que o perito criminal oficial, tendo como princípio a imparcialidade, busca relatar através de sua ótica técnico-científica a verdade dos fatos, com base na lógica e na razão; não objetivando, portanto a condenação. Ainda assim, estabelecidos os critérios para determinação da importância atribuída às perícias realizadas segundo os casos, e aplicados os testes estatísticos comparando-se os grupos "citada" e "citada e mencionada" têm-se que, a menção dos elementos constantes do trabalho pericial (laudo) relatado pela autoridade judiciária no corpo da sentença revela-se 
importante na determinação da culpa ou absolvição do réu.

\section{CONCLUSÃO}

No julgamento de atos que ferem as leis de natureza civil ou militar, a realização de perícias por profissionais peritos agrega valor na busca pela verdade dos fatos, no cumprimento destas leis e no alcance da justiça social, sendo por isso recomendado o uso processual deste recurso sempre que possível e necessário.

\section{REFERÊNCIAS}

[1] F. Eleutério. Análise do Conceito de Crime. Revista Jurídica Mater Dei. 1(1):183, jul-dez 2001.

[2] BRASIL.Presidência da República. Casa Civil. Subchefia para Assuntos Jurídicos. Decreto - Lei $\mathbf{N}^{\circ}$ 1.001, de 21 de outubro de 1969 - Código Penal Militar. Brasília: Diário Oficial da União, 21 de outubro de 1969a. Disponível em:

http://www.planalto.gov.br/ccivil_03/decreto-

lei/Del1001.htm. Acesso em: 02 maio 2016.

[3] R.F. Paiola. Crime Militar e Transgressão Militar no Âmbito Federal. REGRAD - Revista de Graduação UNIVEM, 1(2): 112-126, 2009.

[4] Brasil. Constituição da República Federativa do Brasil: Texto promulgado de 05 de outubro de 1988. Brasília: Secretaria Especial de Informática do Senado Federal, p. 20-25, 2013a. Disponível em http://www.senado.gov.br/legislacao/const/con1988/ con1988_05.10.1988/con1988.pdf>. Acesso em: 20 maio 2016.

[5] M. Hsiao. A Natureza Jurídica do Crime Militar. Revista Eletrônica SapereAude, ano 2, v. 10, maio 2014. Disponível em: $<$ http://revistasapereaude.org/SharedFiles/ Download.aspx?pageid=152\&fileid= 206\&mid=199.>

Acesso em: 25 maio 2015.

[6] Brasil. Presidência da República. Casa Civil.

Subchefia para Assuntos Jurídicos.Decreto - Lei $\mathbf{N}^{\mathbf{0}}$ 1.002, de 21 de outubro de 1969 - Código de Processo Penal Militar. Brasília: Diário Oficial da União, 21 de outubro de 1969b. Disponível em:http:/www.planalto.gov.br/ccivil_03/decretolei/Del1002.htm. Acesso em: 02 de maio 2016.

[7] C. Rosa Filho. A Justiça Militar da União. Revista de Doutrina e Jurisprudência do Superior Tribunal Militar. v. 22, jan-set 2013, parte I.

[8] L.E. Momii, S.T. Amaral. Investigação Forense Judicial.ETIC-Encontro de Iniciação Científica, 3(3):120, 2007.

[9] M.V.R. Goncalves. Novo Curso de Direito Processual Civil, volume 1: teoria geral e processo de conhecimento (primeira parte). 9. ed. Sao Paulo: Saraiva, 2012.

[10] F. J. V. Oliveira. As Provas no Processo Civil. Conteúdo Jurídico, Brasília - DF: 13 jun. 2011. Disponível em: $<$ http://www.conteudojuridico.com.br/?artigos\&ver=2.32 434\&seo=1>. Acesso em: 04 set. 2015.

[11] A.P.L. Amaral. Aspectos da Reforma do Judiciário no Âmbito da Justiça Militar Estadual. Themis Revista da ESMEC. Escola Superior da Magistratura do Estado do Ceará, 4(1):244, jan-jun 2006.

[12] N. Fernandes. A Fundamentação da Decisão Judicial. Da Discricionariedade e Arbritariedade: a Busca da Resposta Correta. Justitia, 66(20), jan-jun 2009.

[13] BRASIL. Poder Judiciário. Justiça Federal de Primeiro Grau em São Paulo. Ação e Sentença Principais Tipos de Ação Leitura Básica de uma Sentença. Núcleo de Comunicação Social - Justiça Federal de Primeiro Grau em São Paulo. 2010, 96p. [14] F.J.A Ribeiro. Justiça Militar, Escabinato e Acesso à Justiça Justa. Amagis Juridica, 5(9):89, jul.-dez.2013

[15] BRASIL. Conselho Nacional de Saúde. Resolução CNS n 466 de 12 de dezembro de 2012. Brasília: Diário Oficial União no 112, 13 de junho de 2013, Seção 1, p. 62. Disponível em: <http://conselho.saude.gov.br/resolucoes/ 2012/Reso466.pdf $>$. Acesso em 30 mar 2016.

[16] F. Souza. Como funciona o tráfico de drogas. Disponível em: $<$ http:// pessoas. hsw.uol.com.br/traficode-drogas.htm> Acesso em: 6 mar 2017. 